\title{
iSALVAD A LOS NIÑOS!: LOS PRIMEROS PASOS DE LA VACUNACIÓN ANTIVARIÓLICA \\ EN ESPAÑA (1799-1805)
}

\author{
Guillermo Olagüe de Ros \\ Dpto. de Anatomía Patológica e Historia de la Ciencia. Granada \\ Mikel Astrain Gallart \\ Dpto. de Anatomía Patológica e Historia de la Ciencia. Granada
}

\section{RESUMEN}

En este trabajo se reconstruyen las primeras fases del proceso de introducción de la vacuna de Edward Jenner en España. Los límites cronológicos del mismo - 1799 y 1805- se corresponden con la fecha de la primera edición de una obra provacunista en nuestro país, y con el edicto de creación de las salas de vacunación en los hospitales peninsulares. Las Academias de Medicina de Madrid y Barcelona, médicos, cirujanos, burgueses y sacerdotes, tuvieron un papel relevante en esta difusión. El Estado, sin embargo, no actúo de forma decidida hasta fechas más tardías. También se estudia la aparición de algunos pícaros que intentaron aprovecharse ante la posibilidad de una falta de pus vacunal.

PALABRAS CLAVE: introducción y difusión de la vacuna jenneriana en España, siglos XVIII y XIX, Academias de Medicina de Madrid y Barcelona, Ignacio María Ruiz de Luzuriaga, libros sobre vacuna, viruela.

\section{SUMMARY}

This paper shows the introduction and evolution of the Jenner's vaccine in Spain between 1799 - date of publication of the first book propicious to the vaccine - and 1805, in which year was promulgated a decree in order to establish wards vaccination in spanish hospitals. Academies of Medicine - basically, Madrid and Barcelona - Physicians, surgeons, middle-classes and priests were responsibles of the large diffusion of Jenner's vaccine in this country, but not the political authorities. Finally, some malicious people are studied as a exponent of the chaotic confussion of this first steps.

KEY WORDS: introduction and diffusion of Jenner's vaccine in Spain, XVIII ${ }^{\text {th }}$ and XIX ${ }^{\text {th }}$ centuries, Academies of Medicine of Madrid and Barcelona, Ignacio María Ruiz de Luzuriaga, printing books on vaccine, smallpox. 


\section{INTRODUCCIÓN}

El descubrimiento de la vacuna antivariólica por Edward Jenner (17491823 ) en mayo de 1796 conoció una difusión espectacular. Apenas dos años después de las primeras experiencias, la vacuna era aplicada con cierta regularidad y mayor entusiasmo en la mayoría de los países europeos. España fue una de las naciones que más tempranamente recurrió a esta medida preventiva. Médicos, burgueses, y en menor medida, clérigos y aristócratas, se convirtieron en los principales difusores de este invento. Las razones por las que tan amplio espectro social se hizo valedor del hallazgo de Jenner son varias. Los médicos, además de por razones técnicas y humanitarias, como una forma de reforzar su status profesional frente a otras profesiones con las que entraban en competencia, como los cirujanos. Los burgueses, mayormente comerciantes, además de por razones filantrópicas como forma de reafirmar su pertenencia a una clase social emergente y de ganarse el respeto de la población. Los cirujanos, obviamente, porque entendían que la vacunación era competencia de su calificación profesional. En fin, los clérigos porque siendo como eran una pieza clave en sus relaciones con el resto de la sociedad, cumplían de esta manera con el principio evangélico de prestar socorro al desvalido y necesitado. La rápida difusión de las práctica vacunal en nuestro país no estuvo exenta de choques de intereses. A pesar de su espectacular expansión no deja de ser significativo que hasta la expedición filantrópica de Balmis — cuestión que es abordada en otro artículo de este número monográfico- el Estado fue incapaz de tomar iniciativas que garantizaran desde el poder un control más efectivo y menos espontáneo de la práctica vacunal. Una de las pocas medidas puestas en marcha, la creación en los centros hospitalarios de salas de vacunación, apenas tuvo incidencia sobre la expansión de la vacuna antivariólica ${ }^{1}$. Incluso, algunos intentos semejantes llevados a cabo en las colonias americanas en el curso de la expedición de Balmis, como en la península de Yucatán, también fueron frustrados, en este caso por conflictos de competencias entre la Península y los regidores coloniales ${ }^{2}$.

El Tribunal del Protomedicato, en franca decadencia en las fechas en que la vacuna de Jenner apareció, fue incapaz, pos su parte, de asumir un papel

1 SANTAMARÍA, E. (1990) «Las salas de vacunación en los hospitales peninsulares a principios de siglo XIX», Dynamis, 10, 303-312.

2 Aceves Pastrana, P.; Morales Cosme, A (1997). «Conflictos y negociaciones en la expedición de Balmis», Estudios de Historia Novohispana, 17, 171-201. [http://www.ejournal. unam.mx /historia_novo/ehn17/EHN01709.pdf (15 de noviembre de 2003)] 
determinante en su proceso difusor. Ignacio María Ruiz de Luzuriaga (17631822), secretario de la Academia de Medicina de Madrid y comisionado por el Tribunal del Protomedicato para informar sobre la vacunación, no pudo influir para que el Tribunal actuara con más protagonismo y eficacia. El informe que concluyó Ruiz de Luzuriaga sobre la vacuna nunca se publicó y permaneció inédito en la Academia. Como ya hemos insistido en anteriores trabajos ${ }^{3}$ el propio Protomedicato, entre cuyas atribuciones se contemplaba la creación de alguna institución que difundiera y velara por el buen funcionamiento de la vacunación, fue incapaz de hacerlo a pesar de las indicaciones en este sentido de algunos médicos, como el mismo Ruiz de Luzuriaga. En su informe el médico vasco concluía con la necesidad de crear en la corte un comité de vacunación centralizador similar a los creados en París y Londres en 1799, lo que no se llevó a cabo. Los motivos de esta desorganización provacunal están directamente relacionados con los problemas organizativos de las profesiones sanitarias (especialmente la medicina y la cirugía) por aquellos años. La reforma interminable de los planes de estudio de las facultades de medicina, la rivalidad de éstas con los Reales Colegios de Cirugía y, en definitiva, la falta de un organismo fuerte y con capacidad efectiva en materia de sanidad en el reino (las juntas de sanidad locales y provinciales estaban escasamente desarrolladas ${ }^{4}$ y el Protomedicato en continuo reajuste) fueron, a nuestro modo de ver, las principales razones de la no puesta en funcionamiento de un organismo regulador de las campañas provacunistas. Tanto la prensa como los propios protagonistas (a través de las cartillas) se encargaron de difundir los beneficios de la vacuna y dar cuenta de los progresos de la misma, sin ningún tipo de amparo oficial, salvo las recomendaciones de las Academias de Medicina.

Fueron las Academias médicas de Madrid y Barcelona, pues, como no podía ser de otro modo, las instituciones que llevaron a cabo el papel de segui-

3 Olagüe de Ros, G.; Astrain Gallart, M. (1994). «Una carta inédita de Ignacio María Ruiz de Luzuriaga (1763-1822) sobre la difusión de la vacuna en España (1801)», Dynamis (Granada), 14, 305-337; OlaGüE De Ros, G.; Astrain Gallart, M. (1995). «Propaganda y filantropismo: los primeros textos sobre la vacuna jenneriana en España (1799-1801)», Medicina e Historia (Barcelona), n. 56, pp. I-XVI; OlAGÜE DE ROS, G. (1995). La introducción de la vacunación jenneriana en España (1799-1805). En: Barona, J. L. (Ed.). Malaltia $i$ Cultura. Trobades. Seminari d'Estudis sobre la Ciència. València. 1994. Valencia, Seminari d'Estudis sobre la Ciència [Guada Litografía, S.L.], pp. 251-273.

4 Rodríguez OCAÑA, E. (1990). «Organización sanitaria española en el siglo XVIII: Las Juntas de Sanidad». En: Fernández Pérez, J.; GonzÁlez TAscón, I. (Eds). Ciencia, Técnica y Estado en la España Ilustrada. Madrid, Ministerio de Educación y Ciencia, Sociedad Española de Historia de las Ciencias, pp. 399-411. 
miento de las vacunaciones en los territorios del Reino. De hecho, ambas instituciones habían jugado un papel destacado en todas aquellas cuestiones que afectaban a la salud de la población, tanto a nivel informativo como práctico. En Barcelona, fueron especialmente activos Francisco Piguillem y Verdaguer (1771-1826) y Vicente Mitjavila y Fisonell (1759-1805), quién publicó en los Diarios de Barcelona los beneficios de la vacuna antes de que fueran publicados en la Gazeta de Madrid. Por su parte, en Madrid jugo un papel determinante el ya citado Ignacio María Ruiz de Luzuriaga, que se convirtió en el principal proveedor de pus vacunal a una buena parte de la península.

\section{Dificultades Para la eXPANSIÓN DE LA VACUNA JENNERIANA EN ESPAÑA DE MANERA CONTROLADA Y EFICAZ: LA AUSENCIA DE UN COMITÉ CENTRAL DE VACUNACIÓN.}

En un informe elaborado en diciembre de 1803 a instancias de la Academia médica madrileña, Ruiz de Luzuriaga apuntaba ya los obstáculos de todo índole con que se encontraban los defensores de la propagación de la vacuna jenneriana en España ${ }^{5}$. Los temores de la población que, todo lo más, prefería la inoculación al nuevo invento de Jenner, y el poco cuidado que ponían los vacunadores en la conservación del fluido, lo que en algunos lugares ocasionaba una carestía de materia prima, eran para Ruiz de Luzuriaga las dos razones fundamentales. Además del poco interés de los padres de niños vacunados para que sus hijos sirvieran de reservorio para nuevas pruebas, lo que impidió contar regularmente con un abundante caudal de pus varioloso ${ }^{6}$.

5 Real Academia Nacional de Medicina (Madrid) [en adelante RANMM], Carpeta 11, doc. 698 (carta de Ruiz de Luzuriaga a la Junta de la Academia de Medicina de Madrid, 21 diciembre 1803). A raíz de un brote epidémico de viruelas en La Coruña (abril de 1804), Antonio Robaines, médico de esa ciudad, ya denunciaba la resistencia de los padres a vacunar a sus hijos y el recurso a «la coacción si no hay voluntarios». Orencio de Santolaria, corregidor de Alcalá la Real (León), informaba a Pedro Ceballos (10 de julio de 1804) que había tomado la determinación «de desterrar de las aldeas las preocupaciones contra una operación tan acreditada» [Archivo Histórico Nacional (Madrid) (en adelante AHN), Estado, Leg. 3215, Exp. 241, docs. 100 y 102].

6 Manuel María González Recomo, comisionado por Orden de 11 de junio de 1806 para propagar la vacuna en Asturias, le señalaba en carta a Ruiz de Luzuriaga (19 de julio) que los asturianos, como los vizcaínos, son poco propensos a desprenderse de sus tradiciones y costumbres, por lo que la vacunación estaba encontrando graves problemas en esos lugares (RANMM, Carpeta 22, doc. 1344). 
Como ya hemos adelantado, el médico vasco propuso la fundación de juntas provacunistas semejantes a las existentes en el extranjero. Lógicamente, el país a imitar era Inglaterra, que

«el 2 de diciembre de 1799 fundó en Londres un establecimiento para fomentar y propagar la vacunación».

Para Juan Peñalver, otro socio de la Academia matritense preocupado por la cuestión, era imprescindible contar con un ejército de decididos partidarios de la vacuna, formado por párrocos, médicos, cirujanos de villas y aldeas, e incluso por los sangradores, a los que les bastaría observar «una breve instrucción que a este fin y para evitar todo error» redactaría esa Comisión Central de Vacunación?.

Sin embargo, frente a la mayoría de los países europeos España no contó con instituciones, públicas o privadas, dedicadas exclusivamente a velar por la expansión de la vacuna. En Londres, por ejemplo, además del organismo mencionado por Ruiz de Luzuriaga - el London Smallpox Hospital- en 1803 se fundó la Royal Jennerian Society, que presidida por el propio Jenner estuvo al tanto de la extensión de la vacuna por Inglaterra. En Italia Luigi Sacco (1769-1836) fue nombrado en 1801 Director de Vacunación de la República Cisalpina y Turín contó desde 1803 con un Comité de Vacunación. En París, entre 1799 y 1803, funcionaron cinco organismos provacunadores ${ }^{8}$.

Un informe totalmente favorable a la vacuna, elaborado por el Colegio de Medicina de Berlín, fue determinante para una intervención estatal de corte proteccionista de esta medida preventiva. Parecidas acciones se ejecutaron en otros países europeos, como Suecia, Austria y Dinamarca, entre otros ${ }^{9}$. Aun-

7 RANMM, Carpeta 11, doc. 698 (Carta de Ruiz de Luzuriaga a la Junta de la Academia de Medicina de Madrid, 21 de diciembre de 1803); Ibid., doc. 700 (Carta de Juan Peñalver a la Junta de la Academia de Medicina de Madrid, s.d., ca. 14 de diciembre de 1803).

8 TuCCI, U. (1984). «Il vaiolo, tra epidemia e prevenzione». En: Della PeruTA, F. (Ed.). Storia d'Italia. Annali 7. Malattia e medicina. Torino, Giulio Einaudi Editore, pp. 388428 (pp. 403-408); DunBAR, R. G. (1941). «The Introduction of the Practice of Vaccination into Napoleonic France», Bull. Hist. Med., 10, 635-650.

9 Mojon, B. (1803). Rapporto sull'innesto della vaccina fatto al Istituto Nazionale di Francia. Tradotto dal Francese dal cittadino.. Genova, Stamperia della Società Medica d'Emulazione, XVI+22 pp. (pp. III-XIII). El informe de Colegio de Medicina de Berlín fue conocido en España gracias a la traducción que del mismo hizo Juan de Rivera y Céspedes (FodÉRÉ, M. (1802). Las Leyes ilustradas por las Ciencias Físicas, ó Tratado de Medicina Legal y de Higiene Pública... traducido por J.D.R.Y.C. Tomo VII, Madrid, en la Imprenta Real, pp. 177-183). 
que, como ha señalado Tucci, se dieron algunos problemas entre vacunadores y autoridades locales por problemas de competencia en la materia, la presencia de estas instituciones permitió una difusión rigurosa y creciente de la nueva técnica preventiva ${ }^{10}$.

En España la única medida de alcance fue la promulgación en 1805 de una Real Cédula por la que se obligaba a la apertura de una sala de vacunación en todos los hospitales ${ }^{11}$. Con dichas salas se pretendía garantizar la permanente presencia de fluido activo en aquellos lugares dotados de nosocomio, y cuantificar estadísticamente los progresos de la vacuna. Pero su cumplimiento fue bastante irregular. Baste a titulo de ejemplo el escaso éxito de la instalada en el Hospital del Amor de Dios de Sevilla que se debió, en parte, a las resistencias de la población, y que ha sido estudiado prolijamente por Encarnación Santamaría. Pero los conflictos entre médicos y cirujanos, por problemas de competencia profesional en el control de las vacunaciones, también debieron de influir en este fracaso ${ }^{12}$. Por todo ello, en 1815, ante la queja de la Academia de Medicina de Murcia por el desuso de la práctica vacunal, el Consejo Real promulgaba una Real Orden que obligaba al cumplimiento de la mencionada Cédula de $1805^{13}$.

A nuestro entender, la ausencia de medidas administrativas de mayor entidad que hubieran garantizado tempranamente un riguroso seguimiento de la práctica vacunal, respondió a la peculiar situación por la que atravesaron durante estos años las profesiones sanitarias, tanto desde el punto de vista educativo como en lo tocante al ejercicio. Inmersas en un complejo proceso de reorganización, y con manifiestos síntomas de inestabilidad operativa, fueron incapaces de prestar una atención corporativa, pero necesaria, a la difusión de la vacunación jenneriana en nuestro país. En efecto, la incapacidad de las Facultades de medicina por llevar a cabo una reforma en profundidad de sus

10 TuCCI, U. (1984), p. 404.

11 Real Cédula de S. M. y Señores del Consejo, por la qual se manda que en todos los hospitales de las Capitales de España se destine una sala para conservar el fluido vacuno... Madrid, Imprenta Real (1805). Algunas iniciativas por crear sociedades de fomento de la vacuna no contaron con el necesario apoyo para su puesta en marcha; tal es el caso de una Sociedad Filantrópica, que quiso promover en Barcelona el médico Vicente Mitjavila y Fisonell [Carta de Vicente Mitjavila a Ruiz de Luzuriaga, Barcelona 19 de agosto de 1801. (RANMM, Papeles sobre la vacuna 1802, Sign.: 23-4 Biblioteca)].

12 SANTAMARÍA, E. (1990), pp. 308-309 y nota 31.

13 Ambas normativas se reproducen en CoRTEZO, C.M. (1903). Datos históricos acerca de la vacuna en España. Leyes y Decretos contra la viruela. Vacunación obligatoria. Madrid, Imp. Católica, La Prensa de Madrid, 123 pp. (pp. 55-68 y 69-70, respectivamente). 
planes de estudio, las cuales estaban además en permanente rivalidad con los Colegios de cirujanos; los continuos vaivenes del Protomedicato, el organismo central encargado del control del ejercicio profesional, suprimido por dos veces —en 1799 y 1804 - y sustituido por Juntas Gubernativas; la poca entidad de las Juntas Provinciales y Municipales de Sanidad, en las que estuvieron parcamente representados los profesionales sanitarios; y la corta vida del poderoso Real Colegio de Medicina de Madrid (1795-1799), preocupado más bien por cuestiones relacionadas con el intrusismo de los cirujanos de la Cor$\mathrm{te}^{14}$, entre otras muchas razones, nos dan razón de esta cortedad legislativa, de la ausencia de organismos sanitarios, centrales y locales, que hubieran promovido con garantías la expansión vacunal, y de tomas de postura colegiadas en el mismo sentido. Por todo ello, la difusión de la vacuna jenneriana en España dependió, con todas sus ventajas e inconvenientes, del entusiasmo personal de los provacunistas ${ }^{15}$.

Tanto la Academia de Medicina de Madrid como la de Barcelona comprendieron precozmente que podían jugar un papel alternativo en materia educativa y sanitaria. Francisco Salvá y Campillo (1751-1828), socio de la de Barcelona, propuso la total supresión de los Colegios de Cirugía como la única medida para frenar su prepotencia ante los médicos. El ya citado Mitjavila, por su parte, en base a un estudio realizado por Salvá acerca de la formación médica en Francia, defendió la idea de suprimir las Facultades y los Colegios y convertir las academias médicas de Madrid y Barcelona en centros docentes, según el modelo francés de las Écoles de Santé16.

14 En las Actas de dicho Colegio se recogen varios casos de intrusismo por parte de cirujanos de la Corte. Por ejemplo, el enfrentamiento de Ruiz de Luzuriaga con Francisco Leyral, cirujano romancista, que se excedió en sus competencias en el tratamiento de un caso de viruela (Actas de las Juntas de Gobierno de 27 y 31 de enero, 3 de febrero, 28 de marzo, 21 y 28 de abril y 5 de mayo de 1797 (ACTAS de las Juntas de Gobierno del Real Colegio de Medicina de Madrid: desde 20 de diciembre de 1795 a 19 de julio de 1799 (RANMM, Catálogo, Carpeta 50)).

15 Calleja Folguera, M. C. (1988). La reforma sanitaria en la España Ilustrada. Madrid, Universidad Complutense.; RODRÍGUEZ OCAÑA, E. (1990).

16 Salvá y CAMPILlO, (1801). Extracto del Proyecto de Ley sobre la instrucción publica en Francia. Dispuesto por el Ciudadano Chaptal... Por Salvá (RANMM, Varios papeles de

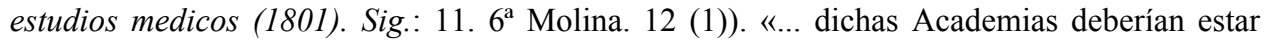
encargadas de la referida enseñanza y las incomparables ventajas que de esto resultarían á la salud pública y al estado, para desengaño de los que no entienden á fondo estas cosas» [Carta de Mitjavila a Ruiz de Luzuriaga, Barcelona, 18 de marzo de 1801. Ibidem, doc. 9]. De los conflictos en la Academia de Barcelona entre médicos y cirujanos en estos momentos, véase la escueta noticia que proporciona CARRERAS I ROCA, M. (1971). Efemérides de la "Real 
Por otro lado, desde el punto de vista sanitario ambas Academias tenían una amplia experiencia. Por petición del Protomedicato, Ruiz de Luzuriaga redactó en torno a estos años varios informes técnicos, además del ya mencionado sobre la vacuna de Jenner: sobre el llamado Cólico de Madrid (1797), un estudio sobre el papel nocivo del plomo y del óxido de cobre para la salud humana; y acerca de las condiciones higiénico-sanitarias de las cárceles de la capital (1803). La academia matritense, además, tenía la competencia de la censura previa de toda obra médica que se fuera a imprimir en el Reino. Esta función permitió a sus socios conocer de primera mano los textos más notables de la medicina e historia natural de su tiempo. Por lo que se refiere a la academia barcelonesa conviene recordar que en agosto de 1796 se le agregó el cargo de Inspector de Epidemias en Cataluña ${ }^{17}$. Socios de la misma realizaron también notables estudios de carácter médico social.

Pero a pesar de que Piguillem y más adelante otros miembros de la Academia Médico-Práctica de Barcelona — como los ya citados Salvá o Vicente Mitjavila - fueron los primeros en recurrir al método preventivo de Jenner en Barcelona, las relaciones de este médico con la Academia - a la cual pertenecía como socio corresponsal desde noviembre de 1790 - nunca fueron muy cordiales en relación con este asunto. Así, en noviembre de 1802, en un informe sobre las actividades vacunadoras de Piguillem solicitado por el Capitán General de Cataluña, un triunvirato de socios, Prats, Salvá y Sanponts, le acusaba de mantener un comportamiento un tanto alegre en este tema, pues había confiado excesivamente en un «médico joven, principiante, y apenas salido de las escuelas de París, François Colon», para iniciar sus vacunaciones, sin querer esperar a que organismos extranjeros con más experiencia en la vacunación, como la comisión francesa de la Société de Médecine, emitieran un informe definitivo sobre la bondad y efectividad del invento. Incluso, otro corresponsal que estaba accidentalmente en Francia, Antonio Martí i Franqués (1750-1832), ya había advertido sobre la conveniencia de mantener una gran cautela antes de que la Academia adoptara una decisión institucional sobre los efectos positivos del nuevo hallazgo. Además, la propia Academia llegó a acusar directamente a Piguillem de obstruccionista, pues había impedido la aparición de la traducción castellana de un texto escrito por un antivacunista reconocido, Alfonso Leroy, efectuada por Tomás Rocondor. Este escrito

\footnotetext{
Academia de Medicina de Barcelona» des d'en Pere Güell a N'Agustí Pedro i Pons. Barcelona, Real Academia de Medicina, pp. 21-22.

17 Carta de Salva á Ruiz de Luzuriaga, Barcelona, 1 de julio de 1801 (RANMM, Varios Papeles de Estudios Médicos (1801), 11-6a Molina 12).
} 
había sido informado favorablemente por la misma institución. No obstante el reconocimiento que le otorgaba en su calidad de precursor de la vacuna, la Academia concluía que era precipitado adoptar una actitud totalmente favorable al hallazgo de Jenner ${ }^{18}$.

Esta reserva de la Academia sobrepasaba los límites de una lógica y necesaria cautela. Si la junta estimaba determinante el informe de los médicos de la comisión parisina para definirse en relación con el nuevo hallazgo, desde el 6 de junio de 1801 se disponía ya de ese informe oficial, que incluso llegó a traducirse al castellano ese mismo año. Es más, la Academia debía tener ya conocimiento de la actitud favorable de la delegación parisina desde enero de $1801^{19}$. El citado naturalista Martí i Franqués, socio corresponsal del liceo barcelonés, sirvió de informante a la corporación barcelonesa sobre el devenir de la vacunación en Londres y París en el curso de un viaje de estudios que realizó a lo largo del año 1800 y prácticamente todo 1801, por varias capitales europeas. De regreso a Tarragona se mostró abiertamente partidario de la nueva técnica ${ }^{20}$. La indecisión de la Academia catalana se mantuvo, siendo así que en enero de 1802 en una sesión plenaria de la misma se acordó no tomar abierto partido por la vacunación, actitud que mantuvo institucionalmente hasta $1818^{21}$. En consecuencia, la Academia madrileña, especialmente a través de su Secretario Ruiz de Luzuriaga, intentó desde el primer momento que se le reconociese un papel determinante en el control y difusión de la vacuna jenneriana en España. Antes de la aprobación de la Real Cédula de 1805, la corporación madrileña solicitó del Rey en octubre de 1801 autorización para dedicar una sala de sus dependencias para efectuar vacunaciones gratuitas,

«evitándose por este medio el que se haga esta operación por imperitos y charlatanes, llevados principalmente de la codicia; pues sin duda estos abusos han obli-

18 El documento, fechado el 10 de diciembre de 1802, se conserva en AHN, Estado, Leg. 3215 , op. cit. en nota (5), doc. 2.

19 GORINA, N. (1987). La penetració de la profilaxi antiverolosa a Catalunya. El problema de les inoculacions. Barcelona, Tesis de Doctorado (inédita), pp. 181-192.

20 Quintana, A. (1935). Antonio de Martí i Franqués. Memòries originals. Estudi biògrafic i documental. Barcelona, López Robert i Cia. (Memòries de l'Acadèmia de Ciències $i$ Arts de Barcelona. Tercera època, Vol. XXIV), p. 125. Sмiтh, J. (1801), Progresos de las vaccina en Tarragona, o instrucciones y reflexiones sucintas sobre la inoculación de la Vacuna, dirigidas a los padres de familia, y a los sugetos que sin ser facultativos se quieran dedicar al fomento y propagación de este admirable descubrimiento en beneficio de la humanidad.... Tarragona, Imprenta de Maria Canals, Viuda, administada por Miguel Puigrubi, pp. 33-34.

21 AHN. Estado, Legajo 3215, Libro 5, Carpeta 28, expte. 28. 
gado ya al rey de Prusia a expedir un decreto con fecha 16 de agosto próximo pasado, prohibiendo que nadie se atreva a Vacunar sin estar aprobado; y que los Cirujanos que hayan obtenido este permiso no puedan usar de él sin el dictamen del Médico» ${ }^{22}$.

El proyecto más ambicioso tuvo lugar en diciembre de 1803. En él, Ruiz de Luzuriaga proponía la creación en Madrid de una Junta Central de Vacunación — que residiría en la Corte- y de Juntas Locales, «al frente de la cuales deberían de estar los Capitanes Generales, Arzobispos, Obispos, Médicos y Cirujanos». Tales Juntas se encargarían del minucioso seguimiento de los casos y de impedir situaciones de desabastecimiento. También solicitaba

«que en la Fábrica de Cristales se monte un taller para aprovechar todos los cristales rotos en que se remitiese el fluido vacuno, cierta franquicia en los Correos, quando se remitiese este fluido sellado con el sello de la Comisión. Y un poco de protección de parte del Gobierno».

Para garantizar la presencia permanente de fluido, el Secretario de la Academia recomendaba

«establecer en la Corte, y en las capitales del Reino, una vacunación metódica y económica en las inclusas, casas de desamparo, hospicios \&c., Y donde no hubiese semejantes establecimientos vacunando con las mismas reglas, y en periodos determinados, cierto número de criaturas de los particulares, conservando este fluido con el esmero que se merece el conservador de la población ${ }^{23}$.

Pero, por desgracia, el plan de Ruiz de Luzuriaga no llegó a aprobarse.

Quizás porque las Academias de Medicina quisieron ser una tercera vía alternativa a la medicina universitaria y a la poderosa cirugía, sus frecuentes choques con la administración del Estado les impidió convertirse en los organismos catalizadores de la expansión vacunal en nuestro país. Salvo la Real Cédula de 1805, ninguna otra medida legislativa arropó el curso del invento de Jenner.

22 «Minuta dirigida al Rey por la Real Academia proponiéndole medidas para difundir la vacunación en Madrid» (s.d., pero octubre de 1801) (Biblioteca de la Real Academia Nacional de Medicina (Madrid), Catálogo, Carpeta 60).

23 SANTAMARÍA, E. (1990). 
3. DIFUSIÓN TÉMPORO-ESPACIAL Y LABOR PROPAGANDÍSTICA EDITORIAL DE LA VACUNACIÓN ANTIVARIÓLICA

Tal como mostramos en los Mapas 1 y 2, fueron tres, básicamente, los focos iniciales de vacunación en la España del periodo que cubre nuestro trabajo. En primer lugar Cataluña, el más temprano. En efecto, a partir del 3 de diciembre de 1800, el médico catalán Francisco Piguillem (1770-1826) procedía a las primeras vacunaciones en Puigcerdá con una muestra remitida desde París por François Colon. La fluida comunicación de la medicina catalana con la francesa, especialmente con la montepesulana, y la larga tradición inoculadora del Principado explicarían, junto con la decidida voluntad de su iniciador, esta precocidad. En Tarragona la personalidad más notable fue Juan Smith y Sinnot (1756-1809), ingeniero del puerto de Tarragona de origen irlandés, que con linfa de Piguillem difundió la vacuna jenneriana por esa provincia y varios puntos de la geografía hispana a partir del 3 de mayo de 1801.

Aunque Aranjuez y Madrid, el segundo núcleo, dependieron en un principio del foco catalán, una serie de fracasos en los primeros ensayos hizo que tan sólo tras la llegada de vacuna fresca procedente de París se iniciara con éxito tal medida preventiva en la capital y en sus alrededores. Con dicho fluido, el médico de la Real Familia Ignacio de Jáuregui y el cirujano Tomás Bueno emprendieron el 22 de abril de 1801 las primeras escarificaciones en Aranjuez. Según Ruiz de Luzuriaga, Luis de Onís, un funcionario de la Secretaría de Estado, le facilitó una muestra procedente de su propia hija, a la que había vacunado Jáuregui; de esta forma pudo iniciar el Secretario de la Academia de medicina matritense el 20 de mayo una serie ininterrumpida de pruebas en Madrid y remitir preparaciones frescas de fluido activo a un amplio grupo de corresponsales, próximos y más alejados, como Juan Manuel de Aréjula (1755-1830) en Andalucía.

El tercer núcleo está constituido por el País vasco-navarro, más disperso geográficamente, y del que sus exponentes más significados fueron Lope García de Mazarredo (1769-1820) en Bilbao, los cirujanos Salvador Bonor, José Antonio de Irizar y Vicente Lubet en San Sebastián, y Diego de Bances y Vicente Martínez en Navarra. En Bilbao los primeros éxitos datan del 22 de agosto de 1801 . A fines de septiembre la vacunación ya era una práctica bastante común en dicha ciudad, a decir de Lope García de Mazarredo. En Pamplona, y a partir de septiembre de 1801, Vicente Martínez ponía en marcha un plan de vacunación con «dos cristales de fluido vacuno» remitidos por el ci- 
tado Ruiz de Luzuriaga ${ }^{24}$. Finalmente, se dio un foco notable en Andalucía, evidente en el Mapa 2, puesto en evidencia por Ruiz de Luzuriaga, probablemente por sus contactos con vacunadores de esta Comunidad, a los que facilitó repetidamente pus vacunal.

\section{MAPA 1: DifUSIÓN ESPACIAL DE LA VACUNA JENNERIANA EN ESPAÑA SEGÚN LA GAZETA DE MADRID (1800-1805)}

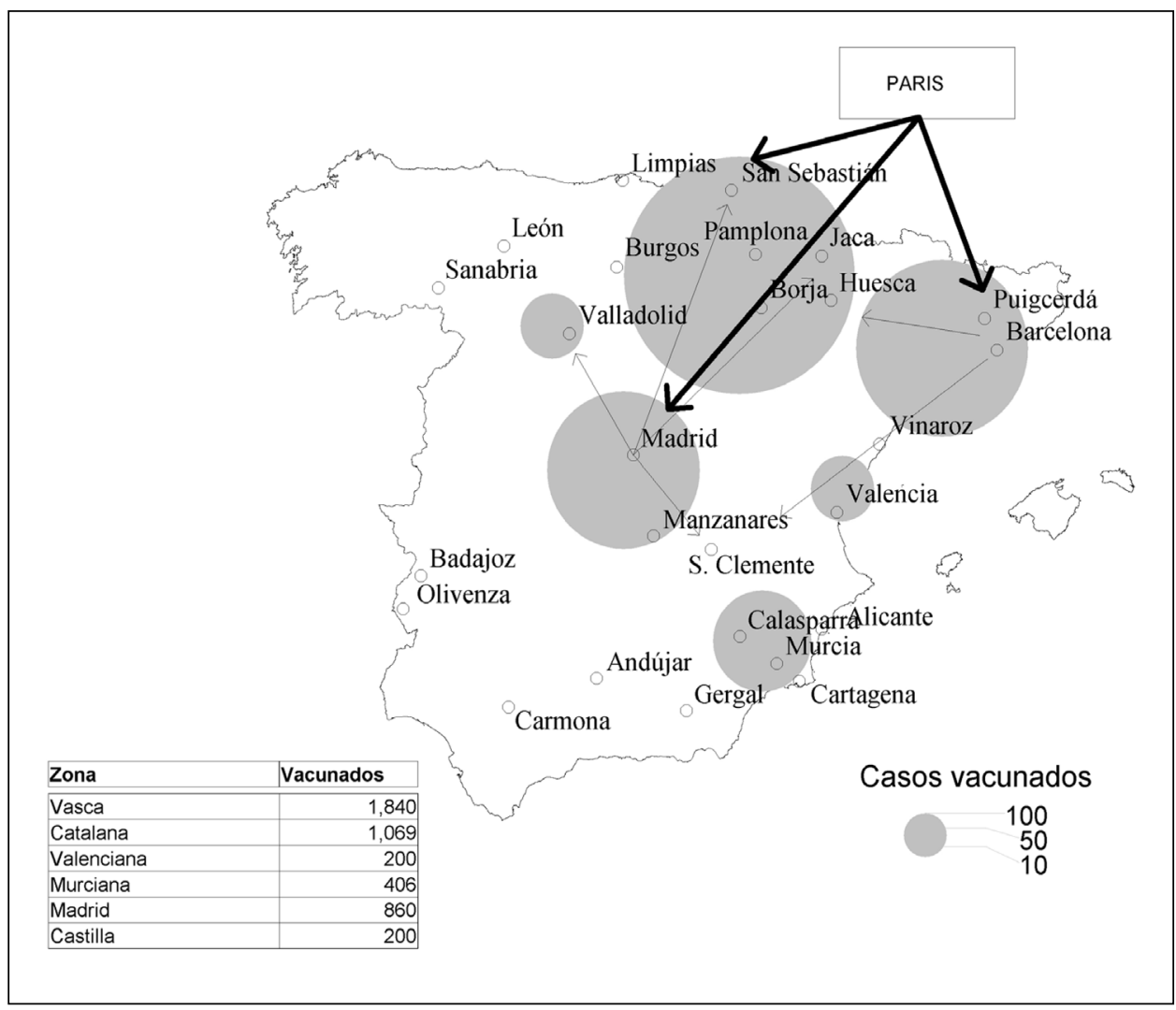

24 Cartas de Lope García de Mazarredo, de 22 de agosto y 29 de septiembre de 1801, a Ruiz de Luzuriaga (RANMM, Papeles sobre la vacuna, 17-2 ${ }^{\mathrm{a}} \mathrm{S}$. Gobierno 18). Sobre el curso de la vacuna en San Sebastián vid. también: DE ARRUTI, E. F. «Descripción topográfico-médica de la Ciudad de San Sebastián». En: GRANJEL, L. S. (1982). Una descripción de San Sebastián de 1826. Salamanca, Instituto de Historia de la Medicina, 22+107 pp. (especialmente las pp. 102-105). 
MAPA 2: DIFUSIÓN ESPACIAL DE LA VACUNA JENNERIANA EN ESPAÑA SEGÚN LUZURIAGA, «INFORME IMPARCIAL...» (1802)

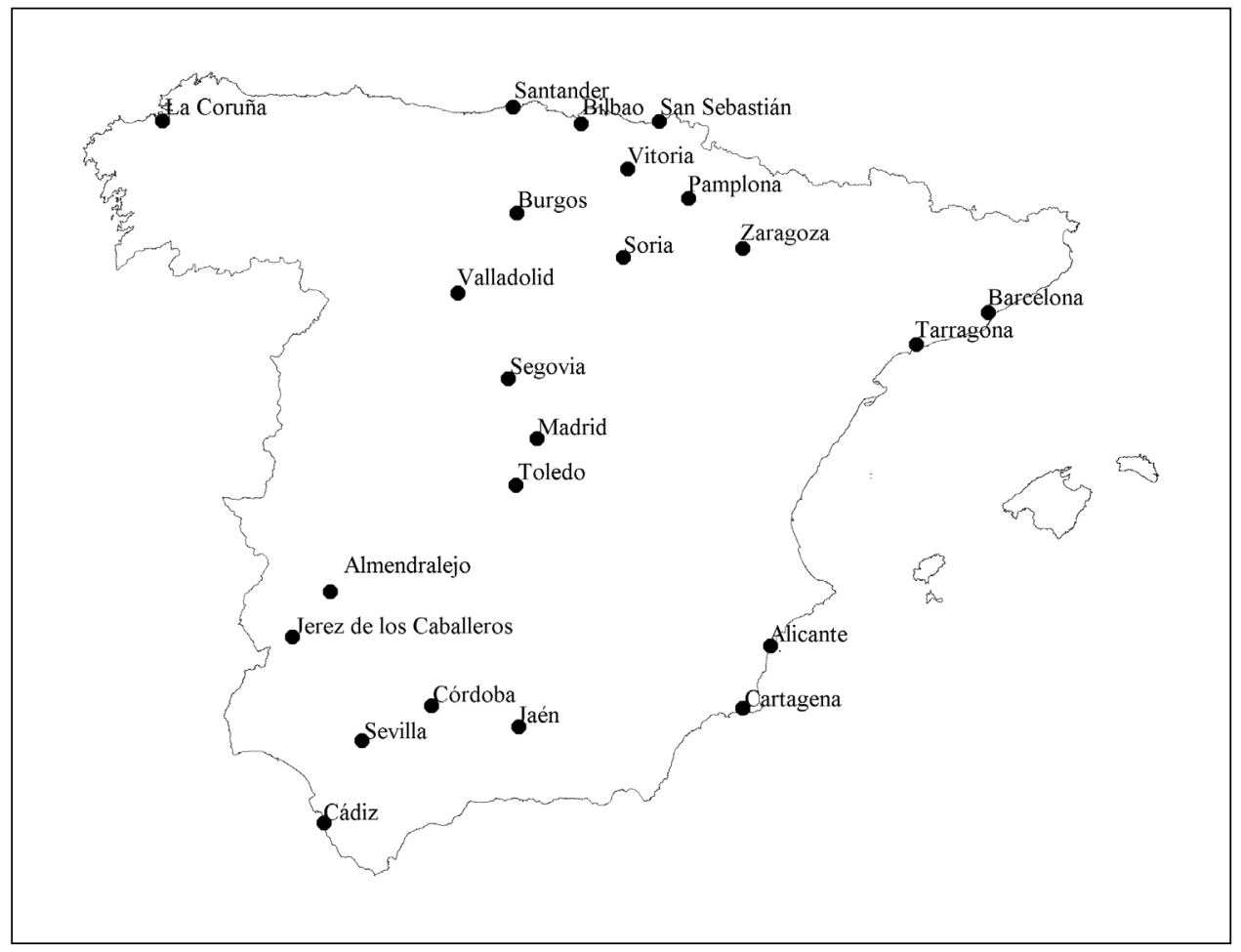

En cuanto a la labor editorial diremos que los canales habitualmente utilizados para comunicar la expansión de la práctica vacunal fueron, por un lado, los impresos (libros, folletos, en buena parte bajo la forma de «cartillas» provacunistas, y artículos periodísticos) y por otro los epistolarios e informes oficiales de las instituciones sanitarias consultadas por los poderes políticos. De tal forma que en el septenio que abarca nuestro estudio se establecieron dos redes de información, una invisible - a través de las correspondencias e informes periciales - y otra visible, constituida por los textos editados y las noticias de la prensa diaria. Conviene adelantar que una y otra se solaparon en contenidos e intencionalidad, pues el objetivo último que perseguían todos los partícipes en este proceso era demostrar la bondad y ventajas de la nueva técnica e, indirectamente, convencer a los responsables políticos de la necesidad 
de adoptar medidas tendentes a garantizar en España la correcta expansión de la vacunación jenneriana.

Desde un punto de vista prosopográfico existe también una clara diferencia entre los distintos soportes informativos. Los autores de los impresos, médicos y cirujanos, formaban parte de la élite profesional sanitaria; mientras que se dio una mayor diversificación ocupacional entre los remitentes de las noticias a la publicación periódica que hemos utilizado como modelo, la $G a$ zeta de Madrid. En efecto, en la Gazeta los sanitarios son mayoritariamente cirujanos, en menor medida médicos, unos y otros residentes especialmente en el medio rural, además de clérigos, corregidores y «vecinos» de dichos lugares. Como ejemplo de información epistolar recurriremos con frecuencia a la rica correspondencia mantenida entre julio y octubre de 1801 con diversos personajes por Ignacio María Ruiz de Luzuriaga.

Entre 1799 y 1805 se publicaron un total de 48 obras, ya sean ediciones o reediciones, en su gran mayoría folletos de corta extensión (media: 39,5 páginas, salvo la traducción el tratado de Moreau de la Sarthe). En el quinquenio comprendido entre 1801 y 1805 la frecuencia de aparición fue de casi un texto al mes, salvo 1803 , en cuyo año sólo vieron la luz cinco obras.

GRÁFICA 1: DISTRIBUCIÓN POR LUGARES DE EDICIÓN DE LOS IMPRESOS SOBRE VACUNA JENNERIANA EN ESPAÑA E HISPANOAMÉRICA

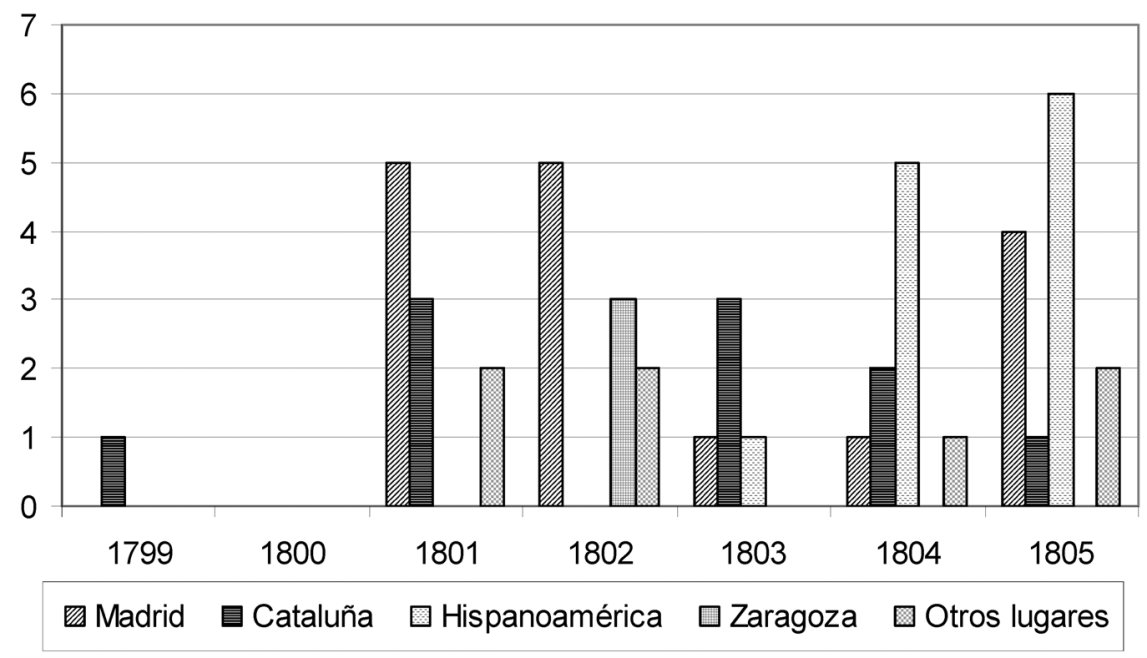

Fuente: Elaboración propia. 
El escrito más temprano es un Compendio de la vaccina (Barcelona, 1799) - una traducción anónima de diversas fuentes francesas- que, como ya hemos comentado en otra ocasión, se muestra partidario tanto de la vacuna como de la inoculación ${ }^{25}$. Por lugares de edición destaca Madrid, con 16 textos, seguida de Hispanoamérica (once), Cataluña (diez), Zaragoza (tres) y otros puntos de la geografías peninsular (8 obras). Los folletos americanos aparecieron en 1804 (cinco) y 1805 (seis), sin duda como una consecuencia directa de la Real Expedición Marítima de la Vacuna (1803-1806) dirigida por Francisco Xavier de Balmis (1753-1819). Los textos aragoneses, los tres de 1802, son debidos al cirujano Francisco Cano y Atrosillo (fl. 1802), si bien de dos de ellos no hemos podido encontrar ejemplar en los catálogos ni en las bibliotecas que hemos consultado ${ }^{26}$.

Nuestra total dependencia informativa del mundo francés es otro aspecto digno de mención. De las 48 obras fueron traducciones 17, todas ellas de originales en ese idioma; como cabe de esperar, su presencia fue más notoria en los primeros años $(1799,1801$ y 1802) y decreció ostensiblemente a partir de 1803 , hasta el punto que en el último trienio se reeditaron monografías galas aparecidas ya en años previos.

Por profesiones de los editores, traductores o autores de textos originales, conviene destacar la mayoritaria presencia de los médicos (veinticinco), seguidos de los eclesiásticos (4, todos ellos hispanoamericanos), dos cirujanos, un médico-cirujano y tres burgueses ilustrados provacunistas, el bilbaíno Lope García de Mazarredo (1769-1820), traductor de Henri Marie Husson (1772-1853), el madrileño Manuel María de Ascargorta y Ramírez (n. 1769), autor de la edición castellana del Primer informe dirigido a la Sociedad de Medicina de París, por la Comisión Médica establecida en aquella capital, en el Louvre... (Madrid, 1801) y de la Breve instrucción sobre la inoculación de la vacuna redactada por el secretario de la misma, Emonot (Ibidem), y el funcionario de la administración Juan de Rivera y Céspedes ( $f l$. 1802), intérprete de François Emmanuel Fodéré (1764-1835). De cinco de ellos no hemos podido determinar ocupación principal. La edad media de los autores de los libros franceses es de 37,5 años; la de sus traductores españoles 39,5 y la de los responsables de los originales españoles 46 años. Un núcleo importante de médicos catalanes, cinco concretamente, se formó en Cervera y tres tuvieron una vinculación notable con la Universidad francesa de Montpellier.

25 Olagüe De Ros, G.; Astrain Gallart, M. (1995).

26 Respuesta á las objeciones que se hacen a la nueva inoculación de la vacuna, dada por el Dr. D. ... Zaragoza, Medardo Heras; Inoculación de la vacuna. Zaragoza, Medardo Heras; Casos de enfermedades ocurridos con motivo de la vacuna. Zaragoza, Of. del Diario. 
TABLA 1: PROFESIONES DE LOS AUTORES DE TEXTOS (TRADUCCIONES Y ORIGINALES) SOBRE VACUNA JENNERIANA IMPRESOS EN ESPAÑA E HISPANOAMÉRICA (1799-1805)

\begin{tabular}{|l|c|}
\hline PROFESIONES & NÚMERO \\
\hline Médicos & 25 \\
\hline Eclesiásticos & 4 \\
\hline Cirujanos & 2 \\
\hline Médico-cirujanos & 1 \\
\hline Burgueses ilustrados & 3 \\
\hline Desconocida & 40 \\
\hline
\end{tabular}

Fuente: Elaboración propia.

Finalmente, y en lo tocante al tipo de soporte, diremos que las cartillas provacunistas y los textos en los que se exhortaba a la población a someterse a la práctica de la vacuna fueron mayoritarios y constantes a lo largo del septenio (veintiuno), seguidos de las monografías (veinte). Las normativas legales, como ya dijimos, fueron consecuencia de la expedición de Balmis; de ahí que su presencia se diera a partir de 1805.
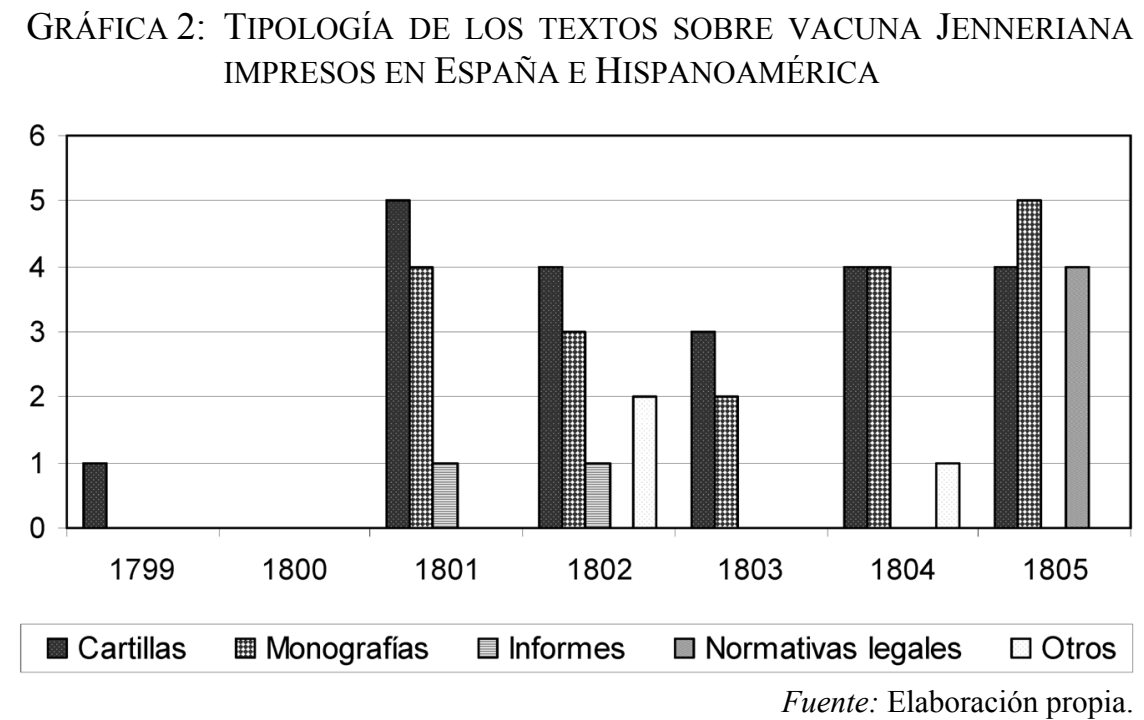
Un seguimiento minucioso de las citas a autores y obras mencionadas en estos escritos nos permite concluir que, implícitamente, todos sus autores mantuvieron entre sí estrechos lazos informativos, bien sea por medio de la lectura de sus respectivos textos, o bien por la existencia de epistolarios. De tal forma que, en estos años, los provacunistas españoles crearon una red comunicativa propia, a través de la cual se intercambiaron noticias sobre sus progresos en la extensión de la práctica jenneriana y, por ende, se hicieron propaganda mutua acerca de sus éxitos vacunales. Significativamente, los vacunados apenas jugaron un papel relevante en los escritos; todo lo más, fueron utilizados por los vacunistas para destacar su «heroicidad», o para magnificar el componente didáctico y ejemplificador de algunos casos notables, habitualmente de miembros de la nobleza, que fueron reiteradamente citados para vencer las resistencias de una población incrédula y temerosa. Es en este contexto de medicalización en el que se entienden mejor ciertas actitudes de algunos provacunistas, como por ejemplo, el enojo del médico Ignacio de Jáuregui (fl. 1801), colaborador habitual de Ruiz de Luzuriaga, por el hecho de que el médico Pedro Hernández (fl. 1801) silenciara, en su Origen y descubrimiento de la Vacci$n a$ (1801), su intensa actividad propagandista en Aranjuez ${ }^{27}$.

En general, el periodismo de la época aportó también abundantes noticias sobre el curso evolutivo de la vacunación en España, a partir de crónicas remitidas por los interesados en su difusión. Es ampliamente conocido que la primera noticia española sobre el descubrimiento de Jenner se insertó en una revista, el Semanario de Agricultura y Artes (1799) ${ }^{28}$. La Gazeta de Madrid, aun no tratándose de una publicación científica, mantuvo una línea informativa provacunista muy intensa a lo largo del tiempo que cubre nuestro estudio. Entre 1799 y 1804, años de los que hemos podido consultar ejemplares de esta publicación, se incluyeron un total de 86 noticias, siendo 1802 el más documentado de todos (46 crónicas). La primera reseña apareció en el número de 6 de enero de 1801. Se trata de una carta fechada en Barcelona el 16 de diciembre del año anterior, en la que se da cuenta de las experiencias realizadas por Francisco Piguillem en Puigcerdá. A diferencia de los impresos, la gran mayoría de los autores de las noticias son sanitarios ejercientes masivamente en el medio rural (51 cirujanos, 30 médicos y 3 médicos-cirujanos), eclesiásticos (ocho), y no facultativos, es decir, comerciantes, corregidores y

27 Sobre la participación de Ignacio de Jáuregui en la introducción de la vacuna en España, vid. nuestro trabajo OlAGÜE DE ROS, G.; ASTRAIN GALLART, M. (1994).

28 Rigau-Perez, J. (1992). «La difusión en Hispanoamérica de las primeras publicaciones españolas sobre vacuna (1799-1804)», Asclepio, 44, 165-179, p. 174, nota. 1. 
«vecinos» de las distintas villas, entre otros (catorce). Se mencionan también dos militares destinados en Extremadura como propagadores de la vacuna.

Pero la Gazeta de Madrid también insertó sucintas notas acerca de la edición de obras projennerianas. Concretamente mencionó a diez entre $1801 \mathrm{y}$ 1804 , en buena parte textos elaborados por comisiones provacunistas francesas, además de algunos originales de los españoles Piguillem, Bances, y Canet y Pons.

Por su condición de Secretario de la Academia de Medicina de Madrid, Ruiz de Luzuriaga mantuvo una intensa correspondencia sobre el curso de la vacuna con diversos personajes de toda España. El médico vasco actuó como propagador de las ventajas de la vacuna y remitió muestras vacunales a individuos de significación social muy clara, en su mayoría médicos, aristócratas y burgueses ilustrados, que compartieron con él los supuestos fisiocráticos y poblacionistas del momento. La peculiar relación de Ruiz de Luzuriaga con el andaluz Juan Manuel de Aréjula, el único cirujano de sus corresponsales, hay que entenderla desde la oposición de éste último a los intentos de acaparamiento del virus vacunal llevados a cabo por los responsables del Colegio de Barcelona ${ }^{29}$.

Apenas transcurrido un año de las primeras pruebas el número de vacunados era ya muy elevado. Solamente en Cataluña superaba los siete mil, mientras que en el resto de España las cifras variaban sensiblemente según el recopilador de los datos.

Para Ruiz de Luzuriaga, hasta casi finales de 1801 se habían vacunado por él mismo o por su directa intervención 1126 personas, de ellas 861 en Madrid y Aranjuez ${ }^{30}$. En otro testimonio inédito del médico vasco, quizás de fecha un poco posterior, los vacunados fuera de la capital ya eran $1480^{31}$. En el Mapa 2 ofrecemos una distribución espacial de los corresponsales a los que Ruiz de Luzuriaga remitió muestras de pus vacunal en el segundo semestre de 1801. Como puede observarse, se aprecia una mayor concentración de núcleos en el

29 La correspondencia de Ruiz de Luzuriaga se conserva en la Academia de Medicina de Madrid. Sobre su particular relación con Juan Manuel de Aréjula, vid.: Cartas de Juan Manuel de Aréjula (Cádiz) a Ruiz de Luzuriaga, de 4 y 25 de agosto de 1801 [RANMM, Papeles sobre la vacuna, 17-2 ${ }^{\mathrm{a}} \mathrm{S}$. Gobierno 18].

30 Vid.: Informe Imparcial sobre el preservativo de las viruelas...(RANMM, Papeles sobre la vacuna 1802, 23-4 ${ }^{\text {a }}$ Biblioteca, fols. 1-48v). Los demás vacunados proceden de Cádiz (65 casos), Soria (200) y Burgos (30).

31 Carta de Ruiz de Luzuriaga a un «Amigo y Señor D. Luis» (s. d.) (RANMM, Papeles sobre la vacuna 1802, 23-4a Biblioteca.) Un análisis de esta epístola en nuestro trabajo: OLAGÜE DE Ros, G.; Astrain Gallart, M. (1994). 
norte peninsular y una ausencia prácticamente total en Valencia y en el antiguo reino de León.

Quizás una de las fuentes impresas más ricas para conocer el curso de la vacunación en España en este momento sea la Gazeta de Madrid. El ya citado Juan de Rivera y Céspedes incluyó los datos de la Gazeta en un capítulo de su traducción del tratado de Fodéré, que dedicó a la expansión de esta medida preventiva en España. Para Rivera, el número de vacunados ascendía en la península a más de seis mil seiscientas personas, en su mayoría residentes en el medio rural, a parte los casos de Cataluña. Según la propia Gazeta, entre 1801 y 1805 eran 15.393 los inyectados, especialmente en 1802 y 1803 (9262 y 5081 casos, respectivamente), con una concentración significativa en Navarra, Castilla la Vieja, Madrid Murcia y Cataluña.

Una texto mucho más tardío, publicado en 1820 por Manuel Gil y Alvéniz, modificaba escasamente los núcleos que hemos señalado hasta ahora como más significativos. En efecto, para este médico titular de Cascante, seguían siendo preminentes Navarra y Castilla la Vieja, aunque ya se hacía evidente una expansión hacia Galicia, Extremadura y Andalucía. En total, Gil y Alvéniz menciona 72 lugares y 82 vacunadores, de ellos un buen número de clérigos y funcionarios estatales, aunque los médicos (doce) y los cirujanos (quince) seguían siendo mayoritarios ${ }^{32}$.

\section{TRES PROPUESTAS DE LA INVENTIVA HISPANA ANTE LOS TEMORES POR UN PROBABLE DESABASTECIMIENTO DEL FLUIDO VACUNO}

Desde muy temprano, los difusores de la vacuna se mostraron francamente preocupados ante la posibilidad de que se diera una posible falta del fluido vacunal, pues el pus antivariólico era exclusivo de las vacas inglesas en las que Jenner había encontrado el remedio para el mal. Incluso los médicos más favorecidos por sus buenas relaciones con sus colegas franceses, fueron francamente conscientes de que, de forma accidental, podía romperse la cadena vacunal ante la no deseada interrupción del pus, como Ruiz de Luzuriaga. Bien es cierto que las sucesivas vacunaciones eran viveros de nuevo fluido, pero ese temor, aun remoto, fue una constante en estos primeros años de difu-

32 Gil y Alvéniz, M. (1820). Colección de Memorias Médicas. Madrid, Ibarra, Impresor de Cámara de S.M., 235 pp. Fue reseñada muy elogiosamente ese mismo año por F.J.L. (Francisco Javier Laso de la Vega) en el Periódico de la Sociedad Médico Quirúrgica de Cádiz (Cádiz), 1, 376-383 (1820). 
sión de la vacuna en España. No es extraño, pues, que en este clima de preocupación algunos sujetos, llevados de la codicia o del afán de notoriedad, intentaran suplir esas posibles carencias con la milagrosa existencia de un pus autóctono, procedente de especies animales propias de la cabaña nacional. Juan José Heydeck —entre 1803 y 1806-, Manuel Hortet y Pauló —a partir de 1804- y las noticias de Quintana en plena campaña expedicionaria de Balmis sobre unas vacas gallegas con vacuna, son tres buenas muestras de picaresca hispana en relación con la cuestión.

Juan José Heydeck, o Moshe Levy, que también era su nombre, era un judío de origen alemán que, tras estudiar en Praga y Oxford, fue nombrado rabino de la Sinagoga de Wesel. En 1783 se convirtió al catolicismo. Tras un periplo por varios países europeos llegó a Madrid, y por su buen conocimiento de varios idiomas fue contratado por la Inquisición como traductor; además se le encargó de la biblioteca en el Real Estudio de San Isidro ${ }^{33}$.

El acercamiento de Heydeck a la vacunación antivariólica conoció dos momentos álgidos. El primero de ellos, en febrero de 1803, respondió a las primeras noticias que el propio Heydeck transmitió al ministro de Estado Pedro Ceballos sobre el hallazgo azaroso de pústulas variolosas en cabras que, inoculadas, preservaban de la viruela con la misma eficacia que las de las vacas, y que tuvo como respuesta el nombramiento en marzo de ese mismo año de una comisión por parte del Protomedicato, de las que formaron parte los socios de la Academia de Medicina matritense Ruiz de Luzuriaga y Pedro Hernández, a los que se sumó en fechas mas tardías Díaz Canedo, cirujano y yerno de Pedro Hernández, quien redactaría posteriormente un interesante informe sobre estas experiencias que, convenientemente manipulado, sería utilizado por Heydeck cuando, en un segundo momento, buscó un respaldo

33 Se pueden rastrear algunas noticias sobre Heydeck en KAYSERLING, M. (1968). Biblioteca Española-Portugueza-Judaica. Nieuwkoop, B. de Graaf, p. 53. (1 ${ }^{\mathrm{a}}$ ed.: Strasbourg, 1890); y AgUilar Piñal, F. (1986). Bibliografia de autores españoles del siglo XVIII. Tomo IV. G-H-I-J$K$. Madrid, C.S.I.C., pp. 462-463, con amplia relación de sus publicaciones. El Legajo 5.441 del AHN., contiene abundante información sobre este judío converso, y de su importancia ya dieron testimonio Antonio Rumeu de Armas y José Simón Díaz. Véanse: RuMEU DE ARMAS, A. (1940). «La inoculación y la vacunación antivariólica en España». Med. Esp. (Valencia), 4, 46-59; $143-$ 154; 233-241; 317-329; 392-410; y, SIMÓN DÍAZ, J. (1948). «La cátedra de Hebreo de los Estudios de San Isidro de Madrid». Sefarad, 8, 97-116 p. 115. Recientemente, Jacobo Israel Garzón ha publicado un estudio, bastante completo e interesante, acerca de este personaje, aunque yerra al atribuirle un protagonismo positivo en el proceso de difusión de la vacuna en España: GARZÓN, J. ISRAEL (2003), «Noticias acerca de Juan Joseph Heydeck, apóstata judío en la España del siglo XVIII». Raíces. Revista Judía de Cultura, 17 (54), 16-28. 
internacional a su hallazgo ${ }^{34}$. Tras diversas pruebas y controles, los comisionados concluyeron que el pus de Heydeck no era un preservativo eficaz contra la viruela, a pesar de la opinión de su descubridor ${ }^{35}$.

El 30 de julio el rey nombraba a su ministro Benito Méndez y a los médicos Ruiz de Luzuriaga y Hernández para que efectuaran vacunaciones controladas en los niños acogidos en la Casa de Amparo madrileña, al objeto de terminar con tan enojosa cuestión. No conocemos documento alguno que narre las peripecias de estas pruebas, aunque en una nota reservada dirigida a la Academia de Medicina, Ruiz de Luzuriaga descalificaba totalmente el hallazgo de Heydeck. Como en España - dice Ruiz de Luzuriaga - no hay vacas que produzcan el fluido vacuno, habrá que recurrir a Berkeley en Gloucester,

«ú otros lugares donde se producen las vacas, ó á qualquiera país, donde lo hubiesen conservado con las vacunaciones practicadas con economía y discrección».

El segundo episodio protagonizado por Heydeck tuvo lugar tres años después, a raíz del conocimiento por nuestros políticos de una noticia sobre el descubrimiento del alemán que había publicado en 1803 una prestigiosa revista médica británica, el Medical and Physical Journal de Londres, que editaban T. A. Bradley y A. F. M. Willich ${ }^{36}$. El firmante de esta nota era William Andrew, un médico inglés de paso por Madrid, que se la dirigió a Richard Dunning, una de las figuras centrales del instituto de Londres que presidía el propio Jenner. El revuelo que se organizó con motivo de esta noticia era expresivo, obviamente, de la sensibilidad de nuestros dirigentes políticos a cualquier aviso que, publicado fuera de España, tuviera que ver con el curso de la vacuna en nuestro país.

Con toda probabilidad fuera el propio Heydeck el que le tradujo al inglés a Andrew todos aquellos documentos demostrativos de su descubrimiento. De todos los escritos aparecidos, los dos más significativos eran la propia carta de Andrew a Dunning y una versión deformada y tendenciosa del informe de

34 Toda la documentación acerca del descubrimiento de Heydeck se conserva en la RANMM, Carpeta 11 (doc. 698), Carpeta 14 (doc. 823), Carpeta 18 (docs. 886, 997 (1, 2 y 3 ) y 1011), Carpeta 21 (doc. 1241) y Carpeta 22 (doc. 1302 (1)); y en el AHN, Estado, Leg. 2932 (2), Exp. 44, docs. 1, 2, 4, 5, 27 y 30.

35 RANMM, Carpeta 18, doc. 997 (2) (Carta de Ruiz de Luzuriaga a M. Gorgullo, s.d.). RANMM, Carpeta 14, doc. 823 (Carta de N. Díaz Canedo al Presidente de la Academia de Medicina de Madrid, s.d., pero junio de 1803)). RANMM, Carpeta 11, doc. 698 (Informe de Ruiz de Luzuriaga a la Junta de la Real Academia de Medicina, 21 diciembre 1803).

36 Medical and Physical Journal (London), n. 56, 339-345 (1803). 
Díaz Canedo, que en la revista aparecía como resultado de la peritación oficial de un «Real Colegio de Médicos» madrileño. Cuando Ceballos, preocupado por lo que decía el periódico británico, consultó en $1805 \mathrm{y}$, de nuevo, un año después, a Ruiz de Luzuriaga sobre la veracidad de la información, su contundente respuesta despejó cualquier duda ${ }^{37}$.

El 22 de febrero de 1804, el médico catalán Marcelo Hortet y Pauló descubrió, según él, azarosamente

«el virus vacuno legítimo y original en los pezones de los pechos de una vacas del labrador Pedro Surroca del lugar de Tosas, del corregimiento de Manresa, partido de Berga».

Vacunó con un poco de ese pus, «en presencia de numerosos testigos», a una niña $\mathrm{y}$, días después, con una muestra procedente de dicha niña, inició una tanda de vacunaciones

«con tanta satisfacción y suceso que después de muchos ensayos se han experimentado la misma serie de efectos preservativos de las viruelas naturales que del virus vacuno bueno del extranjero» ${ }^{38}$.

Considerando que su hallazgo era de gran trascendencia se lo comunicó a Pedro Ceballos, al que además solicitó por tan notable observación un nombramiento efectivo de Director de la Vacunación en Cataluña, con derecho a pensión. Pero Ceballos, no muy conforme con los resultados, le exigió que buscara otras vacas posibles portadoras del virus y que repitiera los experimentos. Una muestra de su pus, envuelta apropiadamente en vidrios, fue remetida a la Academia Médico Práctica de Barcelona y, a través del Capitán General de Cataluña, al propio Ceballos, el cual envió en el mes de julio toda la documentación y los cristales al Secretario de la Academia de Medicina de Madrid. A petición de Ruiz de Luzuriaga, Ceballos dio orden ese mismo mes a la Casa de

37 Concretamente, una carta remitida a Pedro Ceballos el 18 de febrero de 1803, la respuesta de éste (25 de febrero), la comunicación del Ministro a la Junta de la Academia de Medicina de Madrid en la que le exhortaba a comprobar experimentalmente el descubrimiento del alemán, y la nota de Gorgullo a Heydeck en la que le informaba que los médicos de la Academia, Ruiz de Luzuriaga y Hernández, habían sido comisionados por aquella para verificar su descubrimiento.

38 La información que hemos manejado sobre el caso de Hortet procede del AHN, Estado, Leg. 2932 (2), Exp. 48 (docs. 1, 2, 19, 24, 33, 35, 48); y de la RANMM, Carpeta 19 (docs. 1111 y 1114), Carpeta 21 (doc. 1285), Carpeta 22 (doc. 1302 (1 y 2)) y Carpeta 28 (doc. 1721). 
los Desamparados para que Ruiz de Luzuriaga, José Martínez de San Martín y Juan de Azaola, Cirujano de los Reales Hospitales General y Pasión, que habían sido nombrados comisionados en este asunto, pudieran realizar las pruebas pertinentes. Algunos ensayos realizados con dicho fluido concluyeron con un estrepitoso fracaso, por lo que la Academia de Madrid terminaba su informe apuntando la escasa utilidad del hallazgo del médico catalán. Las conclusiones de los expertos madrileños llegaron a manos de Hortet, que las criticó injustamente, en opinión de Ruiz de Luzuriaga, ante la Junta Superior Gubernativa de Medicina. Desoyendo los consejos de los académicos de la Corte, Hortet siguió con sus ensayos en Cataluña, con escasa fortuna y creciente peligro, ya que uno de los niños vacunados falleció por esta causa.

Deseoso de difundir con amplitud el resultado de sus pruebas, Hortet envió una breve noticia al Diario de Valencia, que la publicó los días 6 y 7 de noviembre. El mismo texto lo editó ese mismo año, de forma anónima, en Vich como un folleto, aunque firmado con sus iniciales. En él daba por sentado que

«las vacas españolas están sujetas al cow-pox una vez en la vida, siendo nodrizas o lecheras y por consiguiente no se necesita ahora ya hacer venir el virus vacuno a España de otra nación extranjera» ${ }^{39}$.

Más tarde, y en el Diario de Barcelona de 21 y 22 de enero de 1805, daba a luz nuevas noticias que, igualmente, aparecieron de forma independiente como un opúsculo, más extenso que el primero, pero no muy diferente desde el punto de vista doctrinal ${ }^{40}$.

En noviembre de 1805, Ceballos enviaba a Ruiz Luzuriaga los resultados de las pruebas hechas por la Academia Médico Práctica de Barcelona. Según Ceballos ninguno de los socios enviados a Ribas

39 Relación del descubrimiento del cow-pox en las vacas de los apriscos del valle de Ribas y baronía de Tosas, en el Principado de Cataluña. Vich, oficina de Dorca, 3 pp. (1804). Al fin: 7 de noviembre de 1804.

40 Carta escrita por Don... Médico del Valle de Ribas y de los Exércitos de S.R.M. a ciertos sujetos de la ciudad de Valencia, comunicándoles algunos elementos de la vacuna reducidos a setenta y tres preguntas. Vich, Imprenta de Tolosa, 1 h., 26 pp.+fe de erratas (fechada en Planolas, 20 de febrero de 1805). No hemos localizado ejemplar de una tercera obra de Hortet, aparecida en 1804, que referencian prácticamente todos los repertorios bio-bibliográficos consultados por nosotros: Reflexiones sobre la vacunación, y descubrimiento de la vacuna en los valles de Ribas y Tosas, en Cataluña. Por D. ... Licenciado en Medicina, Médico de número de los reales Exércitos de S.M.C. y Capitán de Migueletes del tercio de Vich en el Principado de Cataluña. Vich, en la oficina de Juan Dorca. 
«halló en todo aquel país a nadie que hubiese visto que las vacas padeciesen aquella enfermedad; ni los pastores más viejos la habían observado. Los Médicos de aquellas poblaciones tampoco la han visto, y se cree que Hortet invacunó alguna vaca, pues se le oyó decir, algunas veces, dentro de tantos días tendré vacas con vacuna».

En los dos años siguientes, las autoridades políticas solicitaron a las más diversas instancias un seguimiento cuidadoso de las experiencias de Hortet, con resultado negativo en todos los casos. Por su parte, los concejales de Planolas definían a Hortet como un individuo «falaz e intrépido, capaz de haber hecho trampas en sus investigaciones $\rangle^{41}$.

Ante tanta evidencia sobre la falsedad del portentoso descubrimiento de Marcelo Hortet, el Rey se vio obligado a intervenir personalmente en tan enojosa cuestión. En efecto, una carta de Palacio al Capitán General de Cataluña en noviembre de 1806 ordenaba a Hortet que «no importune en adelante al Gobierno, imponiéndole perpetuo silencio sobre el asunto».

Del tercer episodio carecemos de más información que la que nos proporciona el Archivo Histórico Nacional. El 27 de julio de 1803 Rafael Costa de Quintana, segun él mismo experimentado vacunador, había observado que las vacas de los valles de Oro y Cadramón, en el Obispado de Orense dan «un fluido semejante al que dan las de los condados de Holstein y Glocester». También ha podido constatar que los que ordeñan las vacas de esos valles no padecen la enfermedad. Ante tan importante noticia, solicita que se comisione un Profesor instruido para verificar si el fluido de las vacas de esos valles de Orense es igual que el del extranjero. Y como si se tratara de un cuento de la lechera, propone llevar a América algunas de las vacas de dichos valles, con lo que se garantizaría una constante provisión de fluido en las colonias. Pero razones de demarcación eclesiástica - esos valles orensanos pertenecían a la diócesis de Mondoñedo, que no a la de Orense- impidió verificar la noticia de Costa de Quintana. Pero poca credibilidad debía de tener, pues no se hicieron mayores esfuerzos en tal sentido. Como el mismo Costa señala en alguno de los escritos, buscaba una compensación por sus esfuerzos, es decir, ser el comisionado que haría el estudio in situ. Pero la cosa no fue a más, como acabamos de indicar. No debemos olvidar, tampoco, que la expedición de Balmis estaba en plena efervescencia por las fechas del informe de Costa y

41 Un extracto de su informe, Reflexiones sobre el cow-pox que el doctor Hortet dijo haber descubierto en las vacas del valle de Rivas, en CHINCHILlA, A. (1846). Anales históricos de la Medicina en general, y biográfico-bibliográfico de la española en particular. Vol. IV, Valencia, Imprenta de José Mateu Cervera, p. 512. 
Quintana, por lo que no es descabellado pensar que Costa estaba buscándose un lugar de privilegio entre los expedicionarios ${ }^{42}$.

\section{CONCLUSIÓN}

Como acabamos de mostrar, la introducción de la vacunación jenneriana en España fue temprana - pocos meses después de su presencia en Franciaeficaz y con un relativo grado de conflicto entre las partes interesadas en su expansión. Además de la vacunación, se contó con unos medios propagandísticos notables, tanto a nivel de libros, folletos como por noticias en la prensa diaria. Médicos, cirujanos — mayoritariamente- y profesionales de la más diversa condición participaron con entusiasmo en su difusión. Hasta el punto que se dio cabida a la presencia de algunos personajes necesitados de fama y con un sentido comercial de dudosa moralidad. Sin embargo, este panorama feliz debe matizarse con los necesarios estudios locales que no den cuenta de la realidad en las diferentes ciudades y zonas españolas por las que se difundió la vacuna. Ya hemos indicado los conflictos del hospital sevillano del Amor de Dios, estudiados por Santamaría. Por su parte, Lola Valverde analizó en 1986 las tensiones en el seno del Hospital General de Pamplona en relación con la vacuna, y las rivalidades por este asunto entre los médicos de este centro y los militares ${ }^{43}$. Probablemente, fueron esas y otras fricciones las que impidieron hasta fechas tardías la intervención del Estado en este asunto. Pero hasta que no se produzcan nuevos acercamientos puntuales, las dificultades y recelos quedarán enmascarados por los éxitos iniciales aquí expuestos.

42 AHN. Estado, Legajo 3215, Libro 6, Carpeta 241, expte. 57 y 58.

43 VALVERDE, L. (1986). «La polémica sobre la inoculación de la vacuna antivariólica en el Hospital General de Pamplona en 1802». En: Actas del I Congreso de Historia de Navarra en los siglos XVIII, XIX y XX. Pamplona, Instituto Jerónimo de Ustaiz, pp. 119-123. 